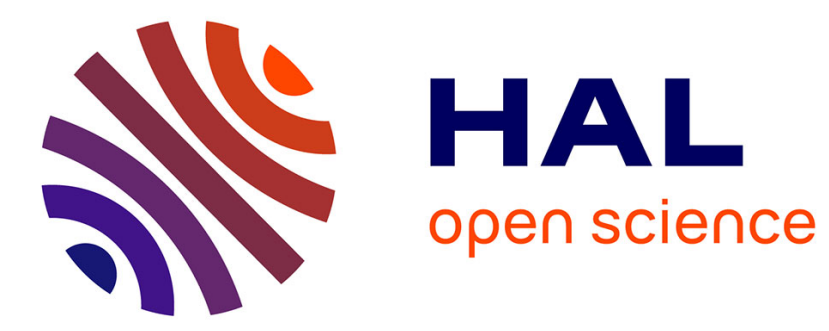

\title{
Acid hydrolysis of native and annealed wheat, potato and pea starches - DSC melting features and chain length distributions of lintnerised starches
}

H. Jacobs, - Eerlingen, - Rouseu, Paul Colonna, Jan Delcour

\section{To cite this version:}

H. Jacobs, - Eerlingen, - Rouseu, Paul Colonna, Jan Delcour. Acid hydrolysis of native and annealed wheat, potato and pea starches - DSC melting features and chain length distributions of lintnerised starches. Carbohydrate Research, 1998, 308, pp.359-371. hal-02695533

\section{HAL Id: hal-02695533 \\ https://hal.inrae.fr/hal-02695533}

Submitted on 1 Jun 2020

HAL is a multi-disciplinary open access archive for the deposit and dissemination of scientific research documents, whether they are published or not. The documents may come from teaching and research institutions in France or abroad, or from public or private research centers.
L'archive ouverte pluridisciplinaire HAL, est destinée au dépôt et à la diffusion de documents scientifiques de niveau recherche, publiés ou non, émanant des établissements d'enseignement et de recherche français ou étrangers, des laboratoires publics ou privés.

\section{(c)(2)}

Distributed under a Creative Commons CCO - Public Domain Dedication| 4.0 International 


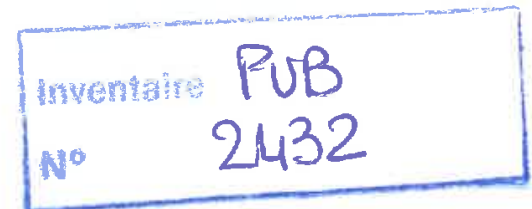

\title{
Acid hydrolysis of native and annealed wheat, potato and pea starches-DSC melting features and chain length distributions of lintnerised starches
}

\author{
Heidi Jacobs ${ }^{\text {a }}$, Relinde C. Eerlingen ${ }^{a}$, Nathalie Rouseu ${ }^{a}$, \\ Paul Colonna ${ }^{\mathrm{b}}$, Jan A. Delcour ${ }^{\mathrm{a}, *}$ \\ ${ }^{a}$ Laboratory of Food Chemistry, Katholieke Universiteit Leuven, Kardinaal Mercierlaan 92, B-3001 \\ Heverlee, Belgium \\ ${ }^{\mathrm{b}}$ Laboratoire de Physico-Chimie des Macromolécules, Institut National de la Recherche Agronomique \\ (INRA), BP 1627, 44316 Nantes, Cedex 03, France
}

Received 10 October 1997; accepted 17 March 1998

\begin{abstract}
Annealing (one and two step) slightly decreased the susceptibility of potato starches to acid hydrolysis (lintnerisation, $2.2 \mathrm{M} \mathrm{HCl}, 35^{\circ} \mathrm{C}$ ); however, it hardly affected that of wheat and pea starches. Annealing had a very pronounced effect on DSC gelatinisation of wheat, potato and pea starches: endothermic peaks narrowed and shifted to a higher temperature. However, already after $10.5 \mathrm{~h}$ of acid hydrolysis, differences in DSC transition temperatures and peak widths between native, one step and two step annealed starches became much smaller and almost disappeared after further hydrolysis, indicating a substantial contribution of the amorphous regions to annealing. The observation that 7-day lintnerised wheat and pea starches were less susceptible to annealing than the corresponding $24-\mathrm{h}$ lintnerised starches supported this view. No changes in chain length distribution were observed between lintnerised (20 days) native and annealed potato starches and between lintnerised ( 7 days) native and annealed pea starches. For all other lintnerised starches, the distribution profiles showed a higher average degree of polymerisation (DP), and a slightly higher ratio of singly branched (DP 22-30) to short linear (DP 10-18) chains (except for 20-day lintnerised pea starches) for the annealed than for the corresponding native starches. This indicates that, as a result of annealing, the amylopectin branch points become more resistant to acid attack. From the above, it was concluded that the amorphous parts in the granule indeed play an important role in the molecular mechanism(s) of annealing, but that structural changes within crystalline parts may also take place. (C) 1998 Élsevier Science Ltd. All rights reserved
\end{abstract}

Keywords: Starch; Annealing; Lintnerisation; Differential scanning calorimetry; Chain length distribution

* Corresponding author. 


\section{Introduction}

Two phases are distinguished in the acid hydrolysis of starch as a function of time. The first phase is attributed to the relatively fast hydrolysis of mainly the amorphous material, while during the second phase a slow hydrolysis of the crystalline material would occur [1-4]. Several factors may account for the protection of crystalline regions. The dense packing of the starch chains in the crystallites does not permit penetration of hydrogen ions, irrespective of the solvation effects. Furthermore, glucosidic links are buried in the interior of the double helix where the hydrogen ions cannot reach them. Finally, in order to be hydrolysed, the glucose unit must undergo a change in conformation from a chair to a half-chair. This conformational change requires a high activation energy as long as the units are held in a crystalline matrix [1].

Insoluble residues after acid hydrolysis of granular starches are referred to as lintnerised starches or naegeli amylodextrins in the case of hydrolysis with $2.2 \mathrm{M} \mathrm{HCl}$ or $15 \% \mathrm{H}_{2} \mathrm{SO}_{4}$, respectively. Generally, it is believed that the residue after prolonged acid hydrolysis consists of acid-resistant crystalline parts of amylopectin [1-5]. Robin et al. [2,3] found two major chain populations in the lintner residues of potato and cereal starches: a linear fraction with mean degree of polymerisation (DP) of 13-15, and a singly branched fraction of DP 25 . Watanabe and French [5] found the same fractions in waxy maize amylodextrins. They also identified a third, higher molecular weight fraction as multiply branched chains. Robin et al. [3] suggested that part of the DP 25 fraction would consist of linear chains of degree of polymerisation (DP) $15-25$, since the DP 25 fraction could not be completely debranched with pullulanase. Linear chains of DP 15-25 are possibly B1 chains of amylopectin (classification of Hizukuri [6]), as identified for amylopectins of different botanical sources, including potato and wheat [6-8]. However, Whelan [9] and Hall and Manners [10] attributed the incomplete debranching with pullulanase and isoamylase of the DP 25 fraction of waxy maize starch amylodextrins to a strong association between A and (newly formed) C chains.

Morrison et al. [11] found that in lintnerised barley starches, apart from the short amylopectin branches (DP 16), two higher molecular weight fractions were present, which were attributed to retrograded amylose (DP 46) and amylose-lipid complexes (DP 77-130). This indicates that amylose-lipid complexes in barley starches are fairly resistant to acid hydrolysis and that amylose chains, after partial hydrolysis, may become sufficiently mobile to aggregate and form resistant double helices.

Annealing of starch is defined as incubation of granular starch in excess water at a temperature above the glass transition but below the gelatinisation temperature. The definition implies that no gelatinisation occurs during the treatment that has significant effects on starch physicochemical properties. In practice, the most pronounced effects of the treatment are obtained at sub-gelatinisation temperatures. The gelatinisation temperature is increased, the gelatinisation temperature range is narrowed and the gelatinisation enthalpy is increased or unchanged [12-14]. Also, the starch pasting properties $[14,15]$ and the susceptibility to enzymatic hydrolysis [16-19] are affected. Annealing does not result in changes in the wide angle $\mathrm{X}$-ray diffraction patterns $[13,20]$. The small angle $\mathrm{X}$-ray diffraction patterns, however, are intensified [21], indicating an increased electron density contrast between crystalline and amorphous regions. No change in repeat distance of crystalline and amorphous lamellae in wheat $(10.5 \mathrm{~nm})$ and potato $(9.9 \mathrm{~nm})$ starches was observed as a result of annealing [21].

So far, the exact molecular mechanism of annealing of granular starches remains unknown. Possible explanations for the observed annealing effects on starch properties include: (i) changes with respect to the crystallinity of the granule [2226], (ii) changes with respect to the amorphous fraction $[12,27,28]$, or (iii) alterations of the interactions between crystallites and the amorphous matrix [13].

The susceptibility of annealed starches to lintnerisation was studied by Hoover and Vasanthan [18]. These authors found a ca. 5\% decrease in the degree of hydrolysis of annealed wheat, potato and lentil starches after 20 days of hydrolysis, but an increased susceptibility $(+14 \%)$ of annealed oat starch.

The purpose of the present study was to gain more insight into the role of the amorphous and crystalline regions in the granule with regard to the molecular mechanism(s) of annealing. Thus, the impact of annealing on the susceptibility of wheat, potato and pea starches to acid hydrolysis was investigated. Furthermore, DSC melting features 
and chain length distributions of lintnerised native, one step and two step annealed starches were determined, and lintnerised starches were subjected to annealing.

\section{Materials and methods}

Materials.-Wheầ (Meriwit I) and potato (Meridal G) starches were from Amylum NV (Aalst, Belgium). Pea starch (Nastar) was from Cosucra (Momalle, Belgium). Maltooligosaccharides (DP 4-10) from corn syrup (M3639) and maltoheptaose (M 7753) were from Sigma Chemical Co. (St Louis, MO).

Differential scanning calorimetry (DSC).-DSC experiments were performed with a Seiko DSC-120 (Kawasaki Kanagawa, Japan). Indium and tin were used as standards. Approximately $5 \mathrm{mg}$ of starch were accurately weighed in an aluminium sample pan. Water was added to obtain a dry matter:water ratio of $1: 2(\mathrm{w} / \mathrm{w})$, sample pans were hermetically sealed and heated from 5 to $150{ }^{\circ} \mathrm{C}$ $\left(4{ }^{\circ} \mathrm{C} / \mathrm{min}\right)$ with an empty pan as reference. The transition temperatures $T_{\mathrm{o}}, T_{\mathrm{p}}$ and $T_{\mathrm{c}}$ are, respectively, the onset, peak and completion temperatures of the gelatinisation endotherm. The enthalpies $(\Delta H)$ of gelatinisation were determined by integration using Seiko software. The reported values are means of triplicate measurements.

Annealing procedure.-Starch suspensions (1:2, $\mathrm{w} / \mathrm{w}$ ) were heated for $24 \mathrm{~h}$ in a sealed container in a water bath at a constant temperature. The annealing temperatures were chosen as a function of the gelatinisation temperature of the native starches, i.e. $3-4 \%$ below the gelatinisation peak temperature (in K) as determined by DSC [14]. After a $24 \mathrm{~h}$ incubation period, the suspensions were Buchnerfiltered and the residues were dried overnight (room temperature, air stream). The resulting starches were referred to as one step annealed starches. Two step annealed starches were prepared by incubating the starch suspensions, after a first period of $24 \mathrm{~h}$ at the first annealing temperature, another $24 \mathrm{~h}$ at a higher temperature, 3-4\% below the gelatinisation peak temperature (in $\mathrm{K}$ ) of the one step annealed starches. After this $48 \mathrm{~h}$ of incubation, the two step annealed starches were isolated in the same way as the one step annealed starches. Annealing temperatures for the first and second step were 48 and $53^{\circ} \mathrm{C}, 50$ and $55^{\circ} \mathrm{C}$, and
50 and $56{ }^{\circ} \mathrm{C}$ for wheat, potato and pea starch, respectively.

Lintnerised starches were annealed for $24 \mathrm{~h}$ in DSC pans (1:2 dry matter:water). The annealing temperatures were chosen $2 \%$ below $T_{0}$ of the lintnerised starches.

Acid hydrolysis.--Native and annealed starches were suspended in $2.2 \mathrm{M} \mathrm{HCl}(1.67 \mathrm{~g}$ dry matter/ $100 \mathrm{~mL}$ ). The closed containers were placed in a water bath at $35^{\circ} \mathrm{C}$ for 20 days and were gently shaken by hand every day in order to resuspend the sedimented granules. At regular time intervals, the solubilised carbohydrates in the centrifuged supernatant $(10 \mathrm{~mL}$ of the homogenised suspension, $15 \mathrm{~min}, 2000 \mathrm{~g}$ ) were determined by the phenol- $\mathrm{H}_{2} \mathrm{SO}_{4}$ method [29]. After 10.5, 24 h, 7 and 20 days of hydrolysis, undissolved residues were isolated by centrifugation $(15 \mathrm{~min}, 2000 \mathrm{~g})$. The residues were washed with deionised water until a $\mathrm{pH}$ of $4.0-5.0$ was reached. Suspensions were then neutralised with $0.1 \mathrm{M} \mathrm{NaOH}$ and washed again with water to remove $\mathrm{NaCl}$. After filtration, the residues were dried at room temperature. Moisture contents were determined with a Metrohm 701 KF Titrino (Metrohm Ltd, Herisau, Switzerland) by the Karl Fischer method [30,31].

Distribution of chain lengths of lintnerised starches.-Chain length distributions of lintner residues of native and annealed starches were determined with size exclusion chromatography (SEC) and high performance anion-exchange chromatography (HPAEC).

High molecular weight $\alpha$-glucans were studied by SEC on a Superose 12TM column (Pharmacia, Uppsala, Sweden; $30 \times 1 \mathrm{~cm}$, eluent $0.1 \mathrm{M} \mathrm{KOH}$, $20 \mathrm{~mL} / \mathrm{h}$ ). Samples $(25 \mathrm{mg}$ ) were solubilised for $24 \mathrm{~h}$ in $1 \mathrm{M} \mathrm{KOH}$ under mild magnetic stirring and then diluted with 9 volumes of water. After filtration, $100 \mu \mathrm{L}$ were injected. The exclusion $\left(V_{0}\right)$ and total $\left(V_{\mathrm{t}}\right)$ volumes were determined using potato amylose and glucose, respectively. Volume fractions $\left(V_{\mathrm{e}}\right)$ of $0.33 \mathrm{~mL}$ were collected and analysed directly for total carbohydrate content by the orcinol- $\mathrm{H}_{2} \mathrm{SO}_{4}$ method [32,33]. $K_{\mathrm{av}}$ is defined as $\left(V_{\mathrm{e}}-V_{\mathrm{o}}\right) /\left(V_{\mathrm{t}}-V_{\mathrm{o}}\right)$.

HPAEC was performed with a Dionex DX 500 (Dionex, Sunnyvale, CA) system. The working and reference electrodes were gold and silver-silver chloride, respectively. An ED 40 electrochemical detector in the pulsed amperometric detection (PAD) mode was used. The following pulse potentials and durations were applied: $E_{1}=0.05 \mathrm{~V}$ 
$\left(t_{1}=200 \mathrm{~ms}\right) ; E_{2}=0.75 \mathrm{~V}\left(t_{2}=200 \mathrm{~ms}\right) ; E_{3}=-0.15 \mathrm{~V}$ $\left(t_{3}=400 \mathrm{~ms}\right)$. The sampling rate of the detector was set to $1 \mathrm{~Hz}$. The Dionex CarboPac PA-100 column $(250 \mathrm{~mm} \times 4 \mathrm{~mm})$ was equipped with a CarboPac PA-100 guard column; the sample loop size was $25 \mu \mathrm{L}$. Eluents were $150 \mathrm{mM} \mathrm{NaOH}$ (eluent A), $150 \mathrm{mM} \mathrm{NaOH}$ containing $500 \mathrm{mM} \mathrm{NaOAc}$ (eluent $\mathrm{B}$ ), and $500 \mathrm{mM} \mathrm{NaOH}$ (eluent $\mathrm{C}$ ). The eluent gradient programme is shown in Table 1 . The eluents were prepared with deionised water $(18 \mathrm{M} \Omega \mathrm{cm})$, filtered through a $0.2 \mu \mathrm{m}$ membrane filter and kept under He pressure (4 psi). The lintnerised starch sample $(25 \mathrm{mg})$ was dissolved in $1.5 \mathrm{M} \mathrm{NaOH}(0.25 \mathrm{~mL})$. Deionised water $(18 \mathrm{M} \Omega \mathrm{cm}, 2.25 \mathrm{~mL})$ was added and the solution was filtered $(0.2 \mu \mathrm{m}$ membrane filter $)$. All samples were run in duplicate. Each run was carried out at $25^{\circ} \mathrm{C}$ with a flow rate of $1.0 \mathrm{~mL} / \mathrm{min}$.

\section{Results and discussion}

Hydrolysis as a function of time.-As mentioned before [1-4], two phases can be distinguished in the lintnerisation profiles (solubilised carbohydrates as a function of time) of native, one step and two step annealed wheat, potato and pea starches. An example is shown in Fig. 1. Repeated experiments (results not shown) revealed that, after one and two step annealing, a small decrease in susceptibility to acid hydrolysis, in the second phase of lintnerisation (from ca. $100 \mathrm{~h}$ onward), could only be detected for potato starch (Fig. 1). This decreased susceptibility of potato starch to acid hydrolysis, as a result of annealing, was also observed by Hoover and Vasanthan [18]. Whereas after 7 days, annealed potato starches were less degraded than the native material, after 20 days,

Table 1

Gradient programme used for HPAEC. Eluents: A, $150 \mathrm{mM}$ $\mathrm{NaOH} ; \mathrm{B}, 150 \mathrm{mM} \mathrm{NaOH}$ containing $500 \mathrm{mM} \mathrm{NaOAc}$; $500 \mathrm{mM} \mathrm{NaOH}$; eluent composition is changed linearly over a specified time. Before every run, the system is equilibrated during $13 \mathrm{~min}$ at initial eluent concentrations

Time (min) Eluent A (\%) Eluent B (\%) Eluent C (\%)

\begin{tabular}{lrrr}
\hline 1 & 80 & 20 & 0 \\
81 & 18 & 82 & 0 \\
$81.1^{\mathrm{a}}$ & 0 & 100 & 0 \\
$82^{\mathrm{a}}$ & 0 & 100 & 0 \\
$83^{\mathrm{a}}$ & 0 & 0 & 100 \\
$88^{\mathrm{a}}$ & 0 & 0 & 100
\end{tabular}

a The last four steps are applied to clean the column.

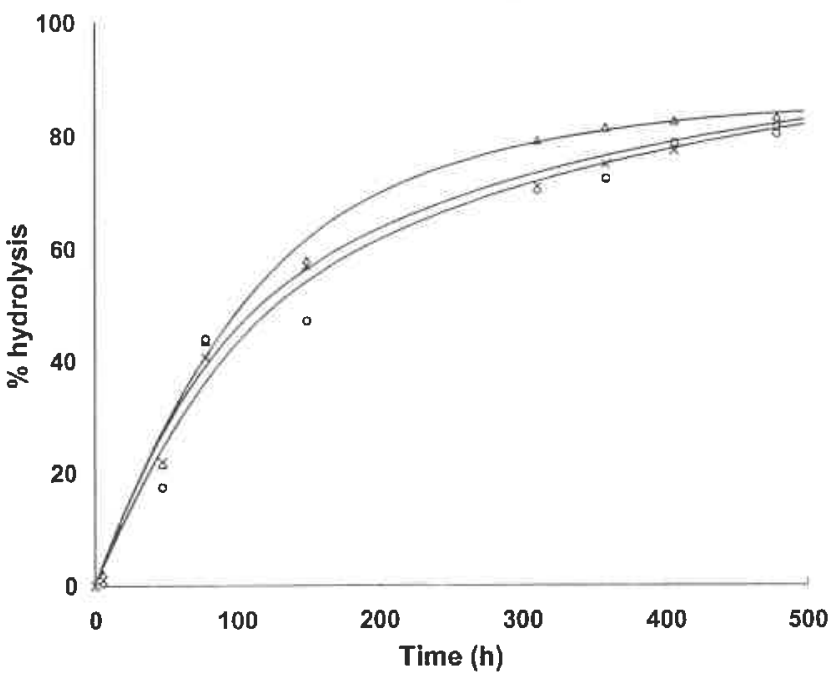

Fig. 1. Lintnerisation $\left(2.2 \mathrm{M} \mathrm{HCl}, 35^{\circ} \mathrm{C}\right.$ ) profiles (solubilised carbohydrates as a function of time) of native $(\Delta)$, one step $(O)$, and two step $(x)$ annealed potato starches.

extents of hydrolysis were similar. This was interpreted as formation of newly organised zones in annealed starches with a resistance intermediate between those of amorphous and crystalline zones. For wheat and pea starches, no significant differences in susceptibility could be observed between native, one step and two step annealed starches (data not shown). In contrast, Hoover and Vasanthan [18] observed a slight decrease in degree of hydrolysis after annealing of wheat starch.

Only very small differences were obtained between the degrees of hydrolysis of lintnerised native, one step and two step annealed starches. Therefore, mean degrees of hydrolysis for these three samples were calculated and are listed in Tables 2-4 (first column, in parentheses) as estimates of the degree of hydrolysis of wheat, potato and pea starches after distinct hydrolysis times. Values for wheat and potato starches agree fairly well with values obtained by Muhr et al. [34] for lintnerised native starches.

DSC melting features as a function of hydrolysis time.-DSC parameters of native, one step and two step annealed wheat, potato and pea starches and of the respective lintnerised starches, isolated after distinct times of acid hydrolysis, are listed in Tables 2-4. Because DSC profiles of wheat and pea starches show the same general trends as those for potato starches, only the latter are shown (Fig. 2).

Wheat starches. Peak $\left(T_{\mathrm{p}}\right)$ and conclusion $\left(T_{\mathrm{c}}\right)$ temperatures increased after $10.5 \mathrm{~h}$ of hydrolysis for native and annealed wheat starches (Table 2). 
Table 2

Thermal characteristics of lintnerised ${ }^{\mathrm{a}}$ native and annealed wheat starches (starch:water $\left.=1: 2 \mathrm{w} / \mathrm{w}\right)$ : onset $\left(T_{\mathrm{o}}\right)$, peak $\left(T_{\mathrm{p}}\right)$ and conclusion $\left(T_{\mathrm{c}}\right)$ temperatures, temperature ranges $\left(T_{\mathrm{c}}-T_{\mathrm{o}}\right)$, and enthalpies $(\Delta H)$; temperatures $\left(T_{\mathrm{am}-1}\right)$ and enthalpies $\left(\Delta H_{\text {am-1 }}\right)$ of dissociation of amylose-lipid complexes (standard deviations in parentheses)

\begin{tabular}{|c|c|c|c|c|c|c|c|}
\hline Wheat starches & $T_{\mathrm{o}}\left({ }^{\circ} \mathrm{C}\right)$ & $T_{\mathrm{p}}\left({ }^{\circ} \mathrm{C}\right)$ & $T_{\mathrm{c}}\left({ }^{\circ} \mathrm{C}\right)$ & $T_{\mathrm{c}}-T_{\mathrm{o}}\left({ }^{\circ} \mathrm{C}\right)$ & $\Delta H(\mathrm{~mJ} / \mathrm{mg})$ & $T_{\mathrm{am}-1}\left({ }^{\circ} \mathrm{C}\right)$ & $\Delta H_{\mathrm{am}-\mathrm{l}}(\mathrm{mJ} / \mathrm{mg})$ \\
\hline \multicolumn{8}{|l|}{ Oh hydrolysis } \\
\hline Native & $54.4(0.0)$ & $58.7(0.1)$ & $63.6(0.1)$ & $9.2(0.1)$ & $11.8(0.3)$ & $102.4(0.5)$ & $0.8(0.1)$ \\
\hline One step annealed & $61.6(0.1)$ & $63.7(0.2)$ & $66.9(0.2)$ & $5.3(0.2)$ & $12.2(0.4)$ & $102.3(0.4)$ & $0.7(0.1)$ \\
\hline Two step annealed & $64.2(0.1)$ & $66.3(0.1)$ & $69.7(0.1)$ & $5.5(0.0)$ & $12.3(0.1)$ & $101.7(0.2)$ & $0.7(0.1)$ \\
\hline \multicolumn{8}{|l|}{$10.5 \mathrm{~h}(9 \%)^{\mathrm{b}}$ hydrolysis } \\
\hline Native & $58.5(0.8)$ & $70.3(0.4)$ & $82.6(1.8)$ & $24.1(2.5)$ & $11.9(0.4)$ & $100.4(0.7)$ & $1.0(0.2)$ \\
\hline One step annealed & $55.0(0.8)$ & $69.4(0.3)$ & $80.3(0.9)$ & $25.4(1.5)$ & $13.0(0.5)$ & $99.7(0.7)$ & $0.8(0.2)$ \\
\hline Two step annealed & $54.9(0.2)$ & $68.7(0.2)$ & $79.3(0.3)$ & $24.4(0.4)$ & $12.9(0.1)$ & $99.6(0.4)$ & $0.5(0.2)$ \\
\hline \multicolumn{8}{|l|}{$24 \mathrm{~h}(18 \%)^{\mathrm{b}}$ hydrolysis } \\
\hline Native & $49.3(0.8)$ & $69.3(0.9)$ & $82.4(0.5)$ & $33.0(1.1)$ & $11.5(1.2)$ & $93.8(1.2)$ & $0.4(0.2)$ \\
\hline One step annealed & $46.9(0.6)$ & $68.5(1.3)$ & $79.5(1.4)$ & $32.6(1.7)$ & $11.4(1.4)$ & $95.4(0.8)$ & $0.7(0.2)$ \\
\hline Two step annealed & $45.3(2.9)$ & $66.3(1.8)$ & $78.3(0.8)$ & $32.8(3.2)$ & $11.6(0.9)$ & $95.0(0.6)$ & $0.9(0.1)$ \\
\hline
\end{tabular}

${ }^{a}$ Values for 7 days $(72 \%)^{\mathrm{b}}$ and 20 days $(89 \%)^{\mathrm{b}}$ hydrolysis were not determined because of the broad undefined endotherms.

${ }^{b}$ Because only very small differences were obtained between degrees of hydrolysis of lintnerised native, one step and two step annealed starches, only mean values are given as estimates of the degree of hydrolysis.

Table 3

Thermal characteristics of lintnerised native and annealed potato starches (starch:water $=1: 2 \mathrm{w} / \mathrm{w})$ : onset $\left(T_{\mathrm{o}}\right)$, peak $\left(T_{\mathrm{p}}\right)$ and conclusion $\left(T_{\mathrm{c}}\right)$ temperatures, temperature ranges $\left(T_{\mathrm{c}}-T_{\mathrm{o}}\right)$ and enthalpies $(\Delta H)$ (standard deviations in parentheses)

\begin{tabular}{|c|c|c|c|c|c|}
\hline Potato starches & $T_{\mathrm{o}}\left({ }^{\circ} \mathrm{C}\right)$ & $T_{\mathrm{p}}\left({ }^{\circ} \mathrm{C}\right)$ & $T_{\mathrm{c}}\left({ }^{\circ} \mathrm{C}\right)$ & $T_{\mathrm{c}}-T_{\mathrm{o}}\left({ }^{\circ} \mathrm{C}\right)$ & $\Delta H(\mathrm{~mJ} / \mathrm{mg})$ \\
\hline $\begin{array}{l}\text { Oh hydrolysis } \\
\text { Native } \\
\text { One step annealed } \\
\text { Two step annealed }\end{array}$ & $\begin{array}{l}58.0(0.2) \\
64.7(0.2) \\
67.3(0.0)\end{array}$ & $\begin{array}{l}62.5(0.1) \\
67.5(0.1) \\
69.8(0.1)\end{array}$ & $\begin{array}{l}70.5(0.8) \\
72.7(0.4) \\
74.2(0.1)\end{array}$ & $\begin{array}{l}12.5(0.7) \\
8.0(0.4) \\
6.9(0.1)\end{array}$ & $\begin{array}{l}18.7(0.5) \\
20.0(0.5) \\
20.5(0.8)\end{array}$ \\
\hline $\begin{array}{l}10.5 \mathrm{~h}(4 \%)^{\mathrm{a}} \text { hydrolysis } \\
\text { Native } \\
\text { One step annealed } \\
\text { Two step annealed }\end{array}$ & $\begin{array}{l}67.3(0.2) \\
68.5(0.1) \\
69.4(0.2)\end{array}$ & $\begin{array}{l}72.9(0.1) \\
74.2(0.2) \\
75.0(0.0)\end{array}$ & $\begin{array}{l}86.1(1.4) \\
85.0(0.4) \\
84.8(0.3)\end{array}$ & $\begin{array}{l}18.8(1.6) \\
16.4(0.3) \\
15.5(0.4)\end{array}$ & $\begin{array}{l}20.5(0.4) \\
20.4(0.5) \\
20.5(0.8)\end{array}$ \\
\hline $\begin{array}{l}24 h(12 \%)^{a} \text { hydrolysis } \\
\text { Native } \\
\text { One step annealed } \\
\text { Two step annealed }\end{array}$ & $\begin{array}{l}62.8(0.4) \\
63.5(0.4) \\
63.8(0.3)\end{array}$ & $\begin{array}{l}76.0(0.4) \\
76.0(0.3) \\
75.9(0.3)\end{array}$ & $\begin{array}{l}88.5(1.0) \\
88.0(0.2) \\
88.2(0.2)\end{array}$ & $\begin{array}{l}25.7(1.3) \\
24.5(0.4) \\
24.4(0.4)\end{array}$ & $\begin{array}{l}23.0(1.3) \\
21.9(0.2) \\
22.0(0.3)\end{array}$ \\
\hline $\begin{array}{l}7 \text { days }(58 \%)^{\text {a }} \text { hydrolysis } \\
\text { Native } \\
\text { One step annealed } \\
\text { Two step annealed }\end{array}$ & $\begin{array}{l}56.9(1.3) \\
57.1(2.3) \\
53.6(4.7)\end{array}$ & $\begin{array}{l}76.5(0.1) \\
75.8(0.5) \\
75.3(0.6)\end{array}$ & $\begin{array}{l}90.8(0.9) \\
90.6(1.1) \\
90.4(1.1)\end{array}$ & $\begin{array}{l}33.8(1.6) \\
33.5(2.5) \\
36.7(5.7)\end{array}$ & $\begin{array}{l}18.6(2.9) \\
18.3(2.8) \\
18.8(4.3)\end{array}$ \\
\hline $\begin{array}{l}20 \text { days }(82 \%)^{\text {a }} \text { hydrolysis } \\
\text { Native } \\
\text { One step annealed } \\
\text { Two step annealed }\end{array}$ & $\begin{array}{l}59.7(1.6) \\
61.0(0.7) \\
60.7(1.3)\end{array}$ & $\begin{array}{l}79.7(0.3) \\
79.2(0.4) \\
80.0(0.5)\end{array}$ & $\begin{array}{l}92.8(1.1) \\
94.2(1.0) \\
91.1(1.0)\end{array}$ & $\begin{array}{l}33.1(2.4) \\
33.2(1.0) \\
30.4(1.1)\end{array}$ & $\begin{array}{l}13.7(1.8) \\
15.1(2.4) \\
9.2(1.5)\end{array}$ \\
\hline
\end{tabular}

${ }^{a}$ Because only very small differences were obtained between degrees of hydrolysis of lintnerised native, one step and two step annealed starches, only mean values are given as estimates of the degree of hydrolysis.

However, after $24 \mathrm{~h}$, no further increase in $T_{\mathrm{p}}$ and $T_{\mathrm{c}}$ was observed. After 7 and 20 days of hydrolysis, the endotherms shifted to higher temperatures, but no exact values of $T_{\mathrm{o}}, T_{\mathrm{p}}$ and $T_{\mathrm{c}}$ could be obtained. The temperature range of the transition increased as a function of hydrolysis time for all three wheat starch samples. The enthalpy $(\Delta H)$ did not substantially change after up to $24 \mathrm{~h}$ of hydrolysis
(Table 2). After 7 and 20 days of hydrolysis, endotherms were undefined and could not be integrated. Approximately the same effects of lintnerisation on gelatinisation temperatures of native wheat starches after 12 and $24 \mathrm{~h}$ of hydrolysis were observed by Muhr et al. [34], although they found a less pronounced increase of the gelatinisation range. In contrast with our results, Muhr et al. [34] noted a 
Table 4

Thermal characteristics of lintnerised ${ }^{a}$ native and annealed pea starches (starch:water $\left.=1: 2 \mathrm{w} / \mathrm{w}\right):$ onset $\left(T_{\mathrm{o}}\right)$, peak $\left(T_{\mathrm{p}}\right)$ and conclusion $\left(T_{\mathrm{c}}\right)$ temperatures, temperature ranges $\left(T_{\mathrm{c}}-T_{\mathrm{o}}\right)$ and enthalpies $(\Delta H)$ (standard deviations in parentheses)

\begin{tabular}{|c|c|c|c|c|c|}
\hline Pea starches & $T_{\mathrm{o}}\left({ }^{\circ} \mathrm{C}\right)$ & $T_{\mathrm{p}}\left({ }^{\circ} \mathrm{C}\right)$ & $T_{\mathrm{c}}\left({ }^{\circ} \mathrm{C}\right)$ & $T_{\mathrm{c}}-T_{\mathrm{o}}\left({ }^{\circ} \mathrm{C}\right)$ & $\Delta H(\mathrm{~mJ} / \mathrm{mg})$ \\
\hline \multicolumn{6}{|l|}{$\begin{array}{l}\text { Oh hydrolysis } \\
\text { Native }\end{array}$} \\
\hline Native & $52.9(0.3)$ & $59.5(0.1)$ & $68.5(0.2)$ & $13.6(0.5)$ & $12.6(0.8)$ \\
\hline One step annealed & $64.6(0.4)$ & $67.1(0.2)$ & $70.5(0.4)$ & $5.9(0.4)$ & $12.6(0.6)$ \\
\hline Two step annealed & $68.1(0.1)$ & $70.2(0.1)$ & $73.4(0.2)$ & $5.4(0.1)$ & $12.2(0.3)$ \\
\hline \multicolumn{6}{|c|}{$\begin{array}{l}10.5 \mathrm{~h}(5 \%)^{\mathrm{b}} \text { hydrolysis } \\
\text { Native }\end{array}$} \\
\hline Native & $64.5(0.2)$ & $70.1(0.0)$ & $77.9(.3)$ & $13.3(0.3)$ & $13.3(0.5$ \\
\hline One step annealed & $64.5(0.7)$ & $71.7(0.2)$ & $80.3(0.6)$ & $15.7(0.5)$ & $13.6(1.2)$ \\
\hline Two step annealed & $65.3(0.1)$ & $72.9(0.1)$ & $82.3(0.6)$ & $17.0(0.6)$ & $12.4(0.3)$ \\
\hline \multicolumn{6}{|c|}{$\begin{array}{l}24 h(13 \%)^{\mathrm{b}} \text { hydrolysis } \\
\text { Native }\end{array}$} \\
\hline Native & $60.7(0.5)$ & $70.9(0.1)$ & $83.8(1.4)$ & $23.1(1.8)$ & $13.0(1.3)$ \\
\hline One step annealed & $56.7(1.4)$ & $71.3(0.3)$ & $83.2(1.6)$ & $26.5(1.2)$ & $12.7(0.4)$ \\
\hline Two step annealed & $58.5(1.6)$ & $72.0(0.2)$ & $88.3(0.4)$ & $29.8(1.6)$ & $12.7(0.4)$ \\
\hline
\end{tabular}

drastic decrease in gelatinisation enthalpy of native wheat starch after $24 \mathrm{~h}$ of hydrolysis.

For wheat starches, a second endotherm was observed near $100{ }^{\circ} \mathrm{C}$ (Table 2). This was attributed to dissociation of amylose-lipid complexes [35]. After 10.5 and $24 \mathrm{~h}$ of hydrolysis, the enthalpy

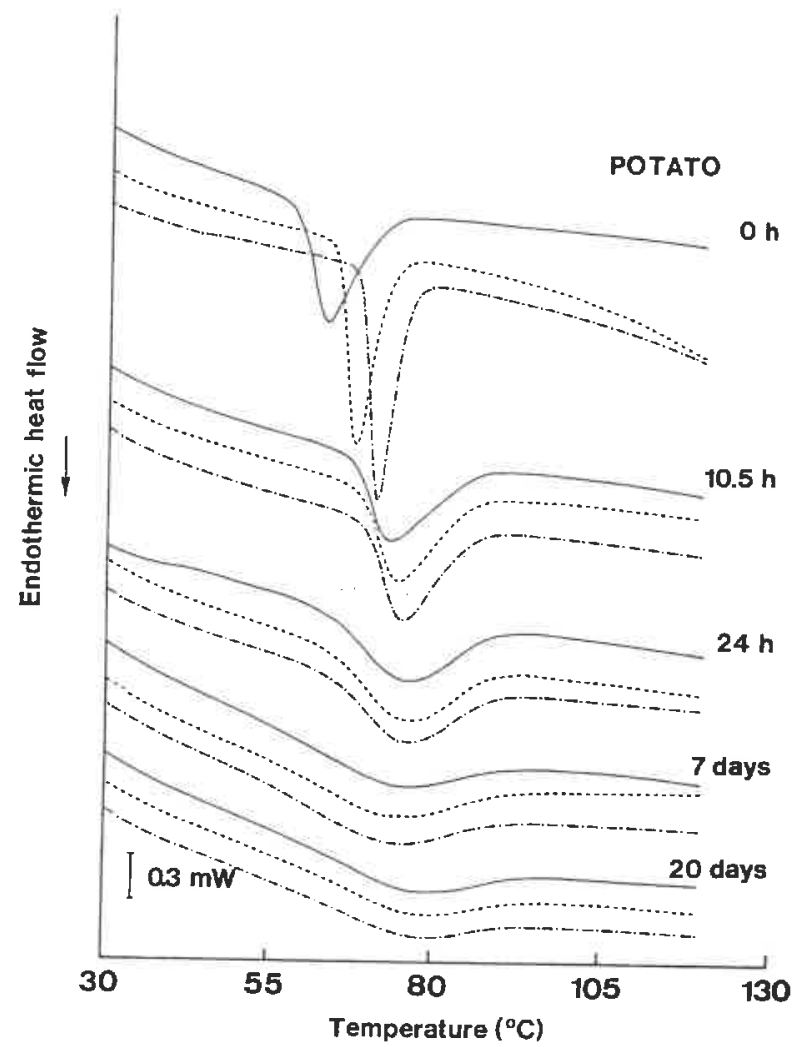

Fig. 2. DSC thermograms of lintnerised native ( - ), one step annealed (--) and two step annealed (-.-) potato starches after $0 \mathrm{~h}, 10.5 \mathrm{~h}, 24 \mathrm{~h}, 7$ days and 20 days of hydrolysis. of dissociation did not change much. After 7 and 20 days of hydrolysis, the amylose-lipid peak could hardly be distinguished.

Potato starches. For native, one step and two step annealed potato starches, $T_{\mathrm{p}}$ and $T_{\mathrm{c}}$ increased with increasing time of hydrolysis, and also the temperature range increased until 7 days of hydrolysis, whereupon no further increase was noted (Fig. 2, Table 3). $\Delta H$ slightly increased after $24 \mathrm{~h}$ of hydrolysis (Table 3 ). For the residues isolated after 7 and 20 days, the endotherms were rather undefined and due to large standard deviations, enthalpies measured after 7 and 20 days of hydrolysis were difficult to interpret. Muhr et al. [34] observed the same trends (although less pronounced) for lintnerised native potato starches, isolated after 12 and $24 \mathrm{~h}$ of hydrolysis, except for a marked decrease in enthalpy, which we did not observe.

Pea starches. For native pea starch, $T_{\mathrm{p}}$ increased after $10.5 \mathrm{~h}$ of hydrolysis for native, one and two step annealed pea starches, but no further increase was noted after $24 \mathrm{~h}$ (Table 4). $T_{\mathrm{c}}$ increased as hydrolysis proceeded. The DSC profiles of the residues isolated after 7 and 20 days seemed to be shifted to higher temperatures. The peak width after $10.5 \mathrm{~h}$ of hydrolysis was unchanged for native pea starch but strongly increased for the annealed pea starches. After $24 \mathrm{~h}$ and more, a further increase in peak width was noted. $\Delta H$ remained approximately unchanged after $24 \mathrm{~h}$ of hydrolysis (Table 4). After 7 and 20 days, again it could not be determined because of the very broad, 
undefined endotherms. An increase in gelatinisation temperature and gelatinisation range was also observed by Biliaderis et al. [36] for smooth pea starch, but these authors observed a decrease in enthalpy after acid hydrolysis.

In general, as a function of hydrolysis time, for native, one step and two step annealed wheat, potato and pea starches, a shift of the endotherms to higher temperatures was observed, together with a peak broadening, without considerable changes in enthalpy (Fig. 2, Tables 2-4). Similar changes as a result of acid hydrolysis were observed before for various native starches [34,36-38]. These changes are attributed to the disappearance of the cooperative melting of the granules, which is facilitated by water uptake in the amorphous parts of the granule [37]. Indeed, according to Donovan's [39] theory, in excess water the amorphous parts in the granules exert a destabilising effect on the crystallites by absorption of water and subsequent swelling because of covalent coupling between amorphous and crystalline parts. Since acid hydrolysis preferentially attacks the amorphous regions in the granule [1-4], the crystallites are decoupled from and no longer destabilised by the amorphous parts. As a result, the crystallites melt at a higher temperature and the transition is broader, indicating the heterogeneous distribution in crystallite stability in the starch granule. Morrison et al. [11] suggested that the higher transition temperature might be due to longer amylopectin double helices than in the unhydrolysed amylopectin molecule, where the branch points might reduce the length of helix forming side chains. As mentioned before, according to Morrison et al. [11], lintnerised barley starches consist not only of crystalline amylopectin side chains (DP 16), but also of retrograded amylose (DP 46) and amyloselipid complexes (DP 77-130). The broad temperature range of the gelatinisation of barley lintners was then assigned to disordering of these different fractions at different temperatures.

Comparison of DSC melting features of lintnerised native, one step and two step annealed starches.-The effect of one and two step annealing on DSC characteristics of wheat, potato and pea starches is very pronounced. The endotherm narrowed and shifted to a higher temperature, and the enthalpy increased or was unchanged (Tables 2-4, Fig. 2, $0 \mathrm{~h}$ hydrolysis). For wheat, potato and pea starches, differences in DSC profiles between native, one and two step annealed starches became smaller as hydrolysis proceeded (Tables 2-4, Fig. 2). For instance, the difference in $T_{\mathrm{p}}$ between native and two step annealed potato starch was $7.3^{\circ} \mathrm{C}$ before acid hydrolysis. Already after $24 \mathrm{~h}$ of hydrolysis, no difference in $T_{\mathrm{p}}$ at all was observed between these two samples (Table 3). Also, the peak width of two step annealed potato starch, which was $5.6{ }^{\circ} \mathrm{C}$ less than for native potato starch before hydrolysis, was of comparable size to that of native starch after $24 \mathrm{~h}$ of hydrolysis. The same observations were made for the other starches.

The changes in melting characteristics induced by annealing became less and less obvious when the starches were subjected to increasing levels of acid hydrolysis. Assuming that amorphous parts are preferentially hydrolysed during lintnerisation [1-4], this indicates a substantial involvement of the bulk amorphous regions and intercrystalline amorphous regions of amylopectin in the annealing process.

Annealing of lintnerised starches.-In order to look further into the contribution of the amorphous parts in the granule to annealing, a selection of lintnerised starches was subjected to annealing. Because the effect of annealing of starches on DSC properties is very pronounced and qualitatively the same for different kinds of starches [14], DSC evaluation was used to study whether, and to what extent, starches, with partially or completely removed amorphous parts, could still be annealed. Because of the rather broad DSC peaks of the lintnerised starches, the annealing temperatures for the lintners were chosen $2 \%$ below $T_{\mathrm{o}}$ (in K), and are listed in Table 5, together with the DSC characteristics of the annealed lintners. Some examples of DSC thermograms are shown in Fig. 3.

For 24-h lintnerised native and one step annealed wheat, potato and pea starches, some effects of annealing on the DSC gelatinisation behaviour were still observed (compare Tables 2-4 with Table 5, Fig. 3a,c,e): a marked increase in $T_{\mathrm{o}}$ was noted, together with a sharpening of the peak, whereas $T_{\mathrm{c}}$ and $\Delta H$ were unchanged. The same effects were still observed after annealing of lintnerised native or one step annealed potato starches, isolated after 7 or 20 days (compare Table 3 with Table 5, Fig. 3d). For the 7-day lintnerised wheat and pea starches, $T_{\mathrm{o}}$ was estimated based on the first derivative of the DSC signal. Here, the peak width seemed to be unaffected, while the endotherm was only slightly more pronounced after the annealing treatment (Fig. 3b,f). Because 
Table 5

DSC characteristics of lintners, isolated after $24 \mathrm{~h}, 7$ or 20 days of hydrolysis and annealed afterwards at $T_{\text {ann }}{ }^{\text {a }}$ during $24 \mathrm{~h}$ in DSC pans (dry matter:water $=1: 2$; means of duplicate measurements)

\begin{tabular}{|c|c|c|c|c|c|c|c|}
\hline Sample & Hydrolysis time & $T_{\mathrm{ann}}{ }^{\mathrm{a}}$ & $T_{\mathrm{o}}\left({ }^{\circ} \mathrm{C}\right)$ & $T_{\mathrm{p}}\left({ }^{\circ} \mathrm{C}\right)$ & $T_{\mathrm{c}}\left({ }^{\circ} \mathrm{C}\right)$ & $T_{\mathrm{c}}-T_{\mathrm{o}}\left({ }^{\circ} \mathrm{C}\right)$ & $\Delta H(\mathrm{~mJ} / \mathrm{mg})$ \\
\hline \multicolumn{8}{|l|}{ Wheat starches } \\
\hline Native & $24 \mathrm{~h}$ & 43 & 58.4 & 67.8 & 80.2 & 21.8 & 10.4 \\
\hline One step annealed & $24 \mathrm{~h}$ & 43 & 57.7 & 66.7 & 79.1 & 21.4 & 9.9 \\
\hline Native $^{\mathrm{b}}$ & 7 days & 54 & - & - & - & - & - \\
\hline Two step annealed ${ }^{b}$ & 7 days & 50 & - & - & - & - & - \\
\hline \multicolumn{8}{|l|}{ Potato starches } \\
\hline Native & $24 \mathrm{~h}$ & 56 & 71.4 & 78.2 & 87.3 & 15.9 & 21.6 \\
\hline One step annealed & $24 \mathrm{~h}$ & 56 & 71.4 & 78.1 & 87.5 & 16.1 & 19.8 \\
\hline Native & 7 days & 50 & 66.3 & 75.5 & 88.0 & 21.7 & 21.4 \\
\hline One step annealed & 7 days & 50 & 66.5 & 75.4 & 87.4 & 20.9 & 20.9 \\
\hline Native & 20 days & 54 & 69.8 & 79.1 & 90.6 & 20.8 & 18.2 \\
\hline \multicolumn{8}{|l|}{ Pea starches } \\
\hline Native & $24 \mathrm{~h}$ & 54 & 69.2 & 75.7 & 83.4 & 14.2 & 14.2 \\
\hline One step annealed & $24 \mathrm{~h}$ & 50 & 65.0 & 73.7 & 82.5 & 17.5 & 13.9 \\
\hline Native $^{\mathrm{b}}$ & 7 days & 54 & - & - & - & - & - \\
\hline Two step annealed & 7 days & 43 & - & - & - & - & - \\
\hline
\end{tabular}

a Annealing temperature of the lintners.

${ }^{\mathrm{b}}$ Values could not be determined.

no large changes in the DSC profiles were noted after annealing of the latter samples (Fig. 3b,f), no attempts were made to anneal 20-day lintnerised wheat and pea starches.After $24 \mathrm{~h}$ of lintnerisation, the degrees of hydrolysis are ca. 18, 12 and 13\% for wheat, potato and pea starches, respectively (Tables 2-4, first column, in parentheses). Since crystallinity has been estimated to be ca. $20-36 \%$ for native wheat and $24-28 \%$ for native potato starches [40,41], the amorphous material is only partially degraded at that time. After 7 days, degrees of hydrolysis of ca. 72, 58 and $59 \%$ are reached for wheat, potato and pea starches, respectively. At that moment, most of the amorphous material is probably removed and the rate of hydrolysis is already strongly decreased (see Fig. 1 for potato starches, results for wheat and pea starches not shown). Degrees of hydrolysis of ca. 89, 82 and $78 \%$, for wheat, potato and pea starches, respectively, after 20 days of hydrolysis, indicate that the remaining residues most likely contain only crystalline material and even part of the crystalline material has been degraded. Indeed, the crystallinity of starches increases with increasing degrees of hydrolysis [2-4,34].

While lintnerised potato starches isolated after $24 \mathrm{~h}, 7$ days or 20 days, all still seem to be susceptible to annealing, 7-day lintnerised wheat and pea starches are less susceptible to annealing than the respective $24 \mathrm{~h}$ lintners (compare Tables 2-4 with Table 5, Fig. 3). Thus, for wheat and pea starches, removal of the amorphous parts in the granule decreases the susceptibility to annealing, reinforcing the hypothesis that amorphous parts play an important role in the molecular mechanism(s) of annealing. However, the fact that the DSC profiles of significantly ( $82 \%$ ) hydrolysed potato starches change as a result of annealing, implies that some structural changes can probably also take place within the crystalline parts (e.g. crystallite perfection), as was already observed for synthetic polymers [42].

Chain length distribution of lintnerised native and annealed starches.-

$S E C$. After 20 days of acid hydrolysis, the SEC chain length distribution profiles of wheat, potato and pea starches were somewhat narrower and slightly shifted to higher $K_{\mathrm{av}}$ than after 7 days (Fig. 4), indicating an (expected) decrease in DP. For 7- and 20-day lintnerised one and two step annealed wheat starches, and for 7-day lintnerised one and two step annealed potato starches, a slight shift of the distribution profile to lower $K_{\mathrm{av}}$ than for the respective lintnerised native starches was observed. These lintnerised annealed starches thus have a higher DP than the respective lintnerised native starches. No visible changes in the chain length distribution profiles of lintnerised native, one step and two step annealed starches were observed for potato samples after 20 days of hydrolysis, and for pea samples after 7 and 20 days of hydrolysis. 


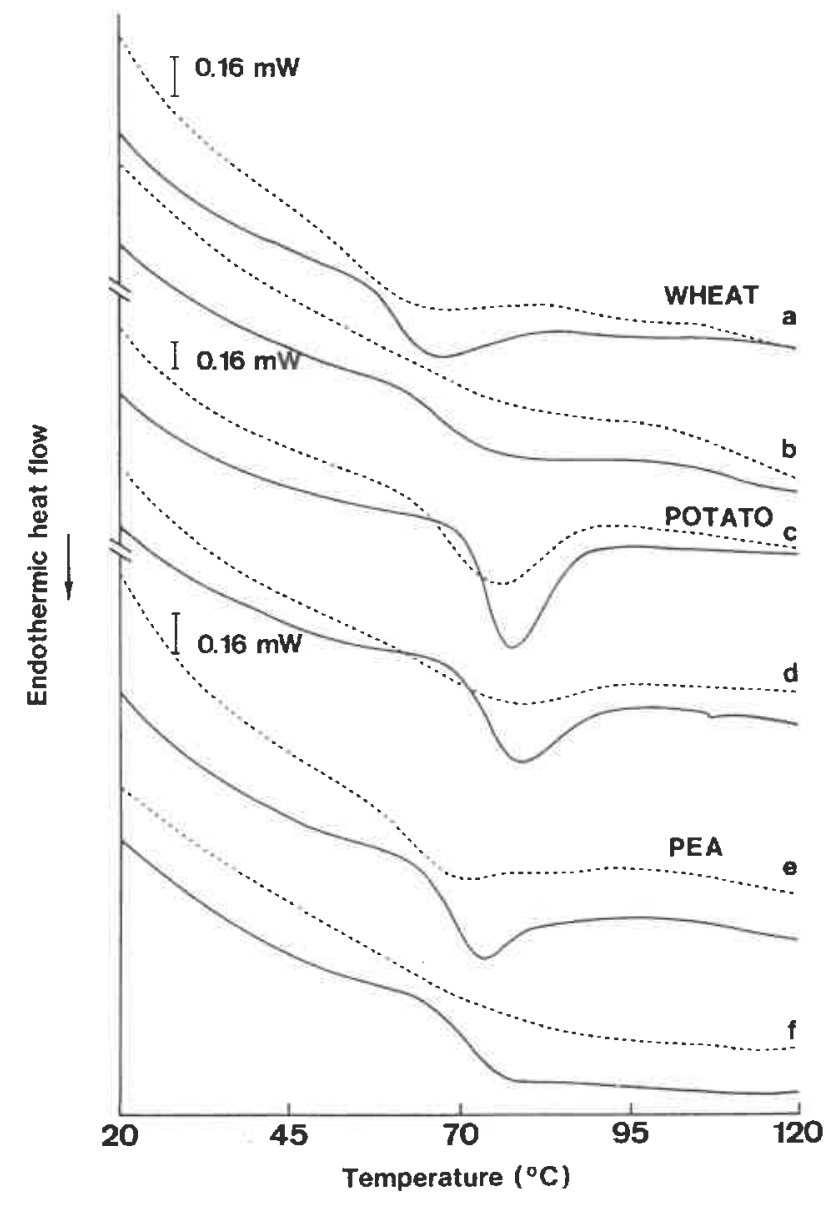

Fig. 3. DSC thermograms, before (-.) and after ($24 \mathrm{~h}$ annealing in DSC pans of: (a) 24-h lintnerised native wheat starches; (b) 7-day lintnerised two step annealed wheat starches; (c) 24-h lintnerised one step annealed potato starches; (d) 20-day lintnerised native potato starches; (e) 24-h lintnerised one step annealed pea starches; (f) 7-day lintnerised two step annealed pea starches.

$H P A E C$. DP values from 4 to 10 were assigned using a mixture of maltooligosaccharides (DP 4 10) and pure maltoheptaose. DP values higher than 10 were assigned by extrapolation. Small peaks between main peaks, and peak shoulders, in the first half of the chromatogram (Fig. 5) probably originate from branched products [43-45].

Generally, two main populations of chains could be distinguished in all lintnerised starches, with peak maxima at DP 13-15 and 25-27 (Fig. 5). For all lintnerised starches investigated, also higher DP chains (DP $>35)$ were present. These observations agree with previous literature results (see Section 1). Possible structures present in lintnerised starches are shown schematically in Fig. 6. The branched nature of DP 25 and higher DP chains was confirmed by HPAEC analysis of debranched (pullulanase (Megazyme), acetate buffer $\mathrm{pH}$ 5.5) 7-day lintnerised potato starch (R.C. Eerlingen, unpublished data).

Because no response factors for individual components are available, the total area of peaks arising from DP 22-30 was divided by the total area of peaks arising from DP $10-18$ as an arbitrary measure of the ratio of singly branched chains to linear short chains (Table 6).

As a function of hydrolysis time, the chain distribution profile indicates a general shift to less long (high retention time) and more short (low retention time) chains (Fig. 5). The ratio of DP 2230 to DP $10-18$ chains was also lower after 20 days than after 7 days of hydrolysis (Table 6). This means that the average DP of the lintners decreases with increasing hydrolysis time, in agreement with SEC results, and that, as a function of hydrolysis time, singly branched chains are hydrolysed to linear chains.

Comparison of chromatograms of lintnerised native and two step annealed starches (Fig. 5) revealed no changes between lintnerised native and two step annealed potato starches, isolated after 20 days and between lintnerised native and two step annealed pea starches, isolated after 7 days. This is in agreement with SEC results (Fig. 4). For all other lintners, however, the relative fraction of high DP chains (DP $>30-40$ ) was higher and the fraction of low DP chains (DP 6-30) was lower for the lintnerised two step annealed starches than for the respective lintnerised native starches. The average DP of these lintnerised annealed starches is therefore higher than for the respective lintnerised native starches, which also followed from SEC results for 7- and 20-day lintnerised wheat starches, and for 7-day lintnerised potato starches. Only for 20-day lintnerised pea starches, the small changes that were visible with HPAEC (Fig. 5) between the chain length distribution profiles of residues of native and two step annealed samples, were not revealed by SEC (Fig. 4).

In the case of 7- and 20-day lintnerised wheat starches, and 7-day lintnerised potato starches, the ratio of singly branched (DP 22-30) to short linear (DP 10-18) chains was observed to be slightly higher for the lintnerised two step annealed starches than for the respective lintnerised native starches (Table 6). For residues of native and two step annealed pea starches, after 20 days of hydrolysis, however, this ratio was unchanged, as for pea starch residues after 7 days, and potato starch residues after 20 days of hydrolysis. 
Wheat - 7 days hydrolysis

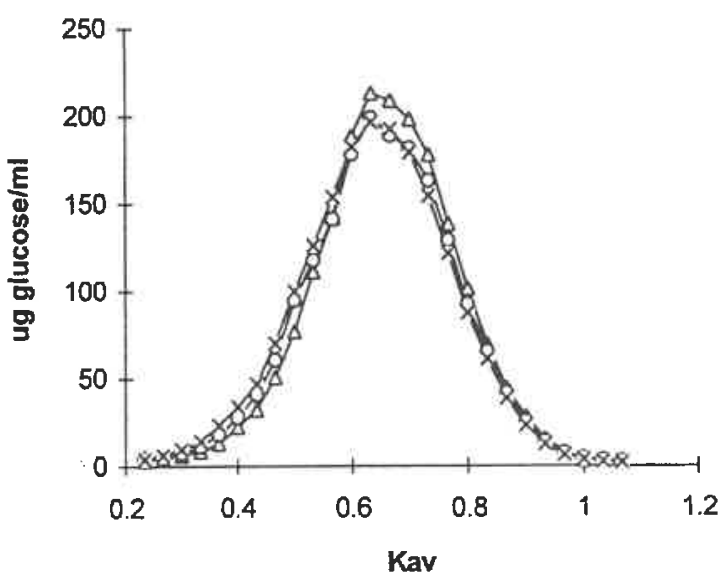

Potato -7 days hydrolysis

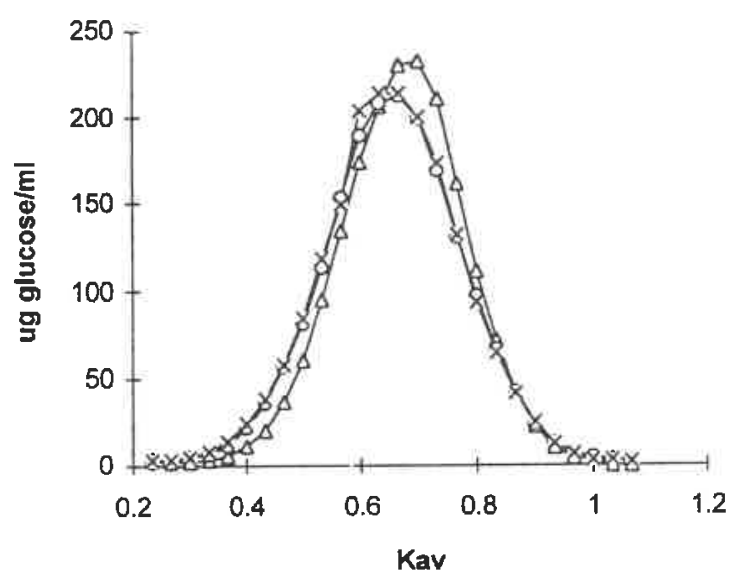

Pea - 7 days hydrolysis

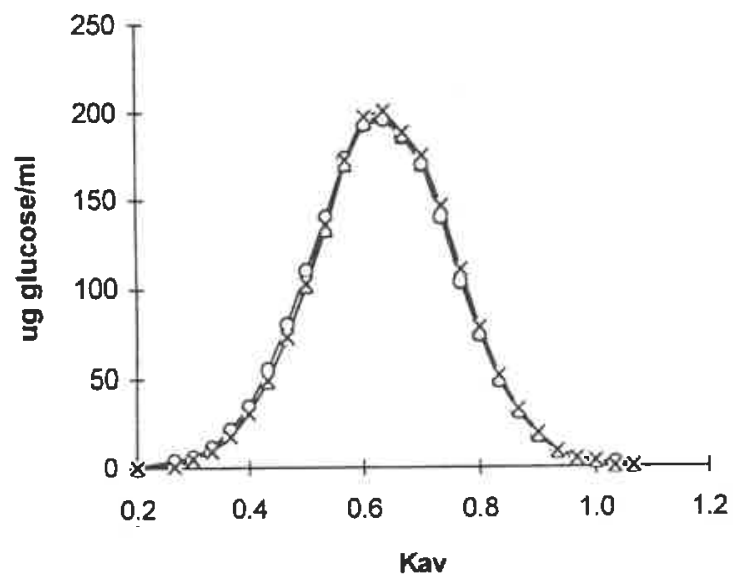

Wheat - 20 days hydrolysis

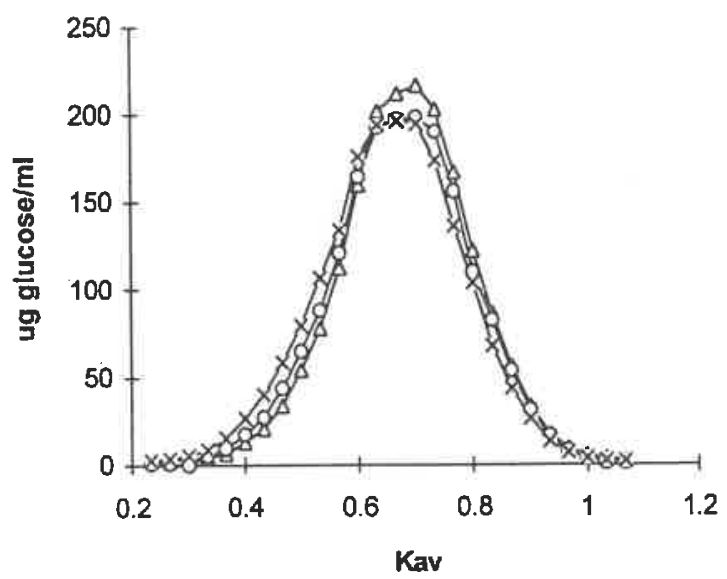

Potato - 20 days hydrolysis

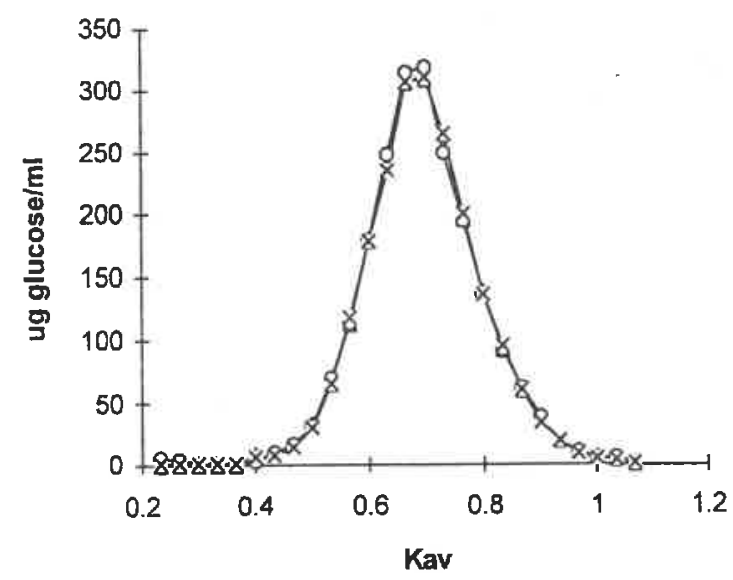

Pea - 20 days hydrolysis

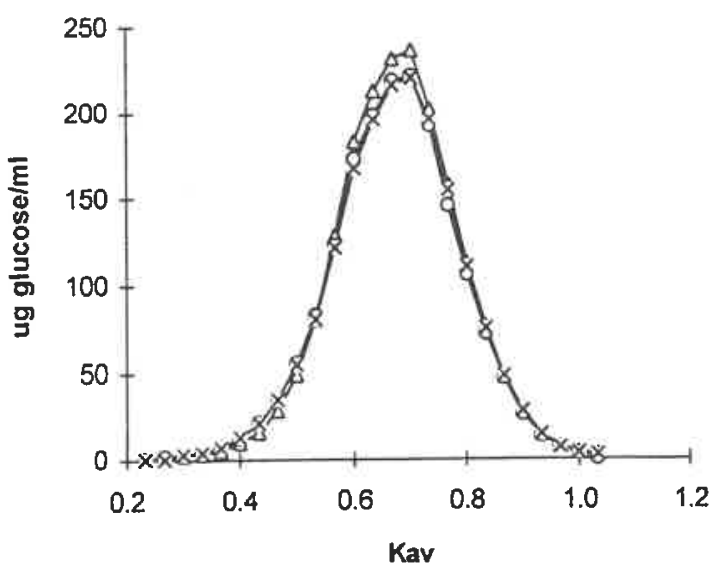

Fig. 4. SEC chain length distribution profiles of lintnerised native $(\triangle)$, one step annealed $(O)$, and two step annealed $(x)$ wheat, potato and pea starches. 
Wheat - 7 days hydrolysis

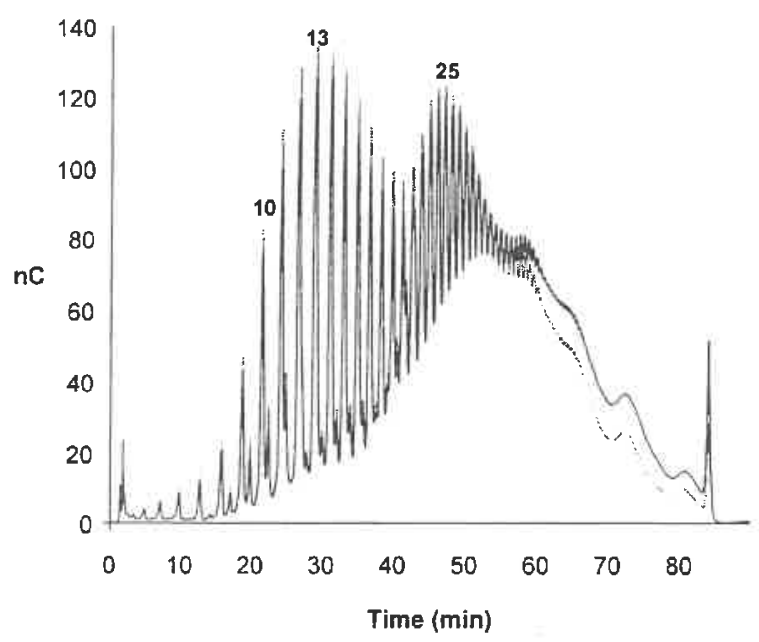

Potato - 7 days hydrolysis

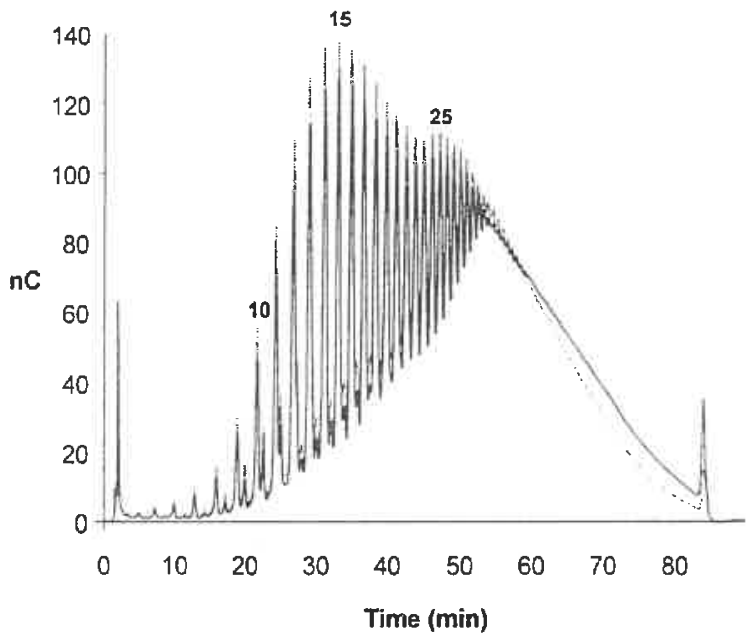

Pea - 7 days hydrolysis

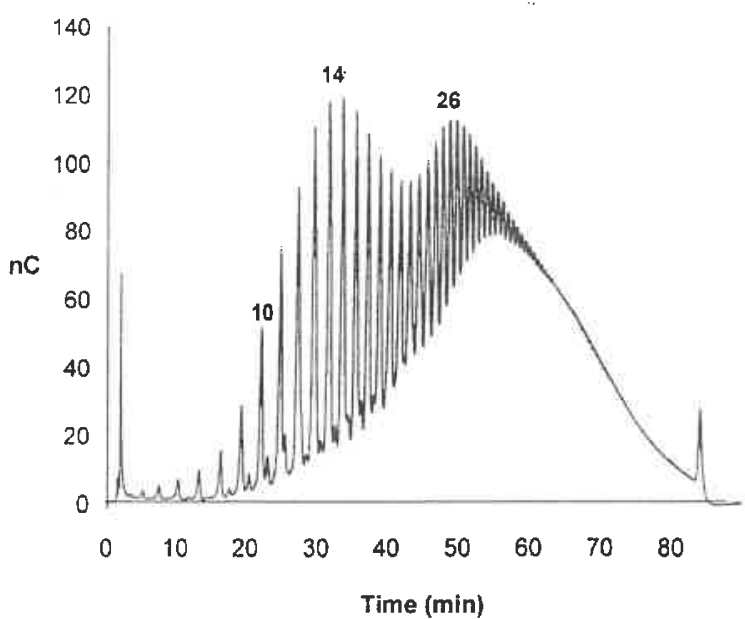

Wheat - 20 days hydrolysis

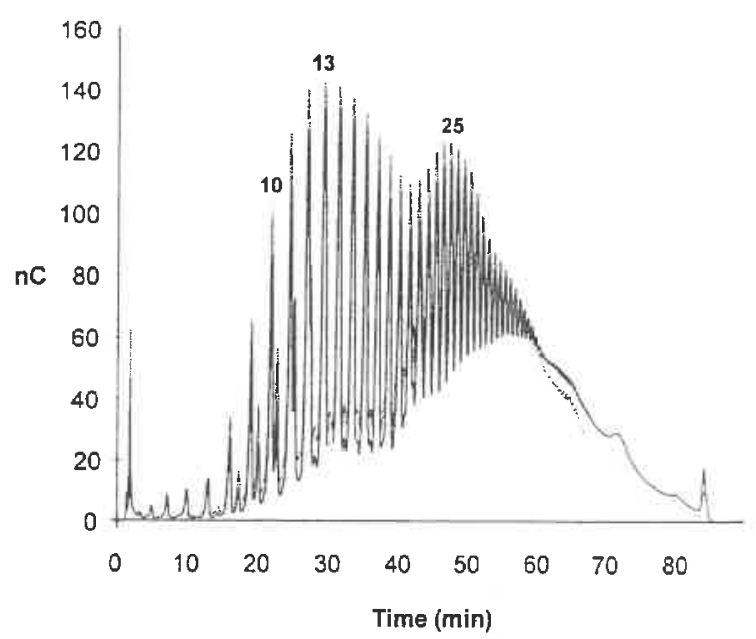

Potato - 20 days hydrolysis

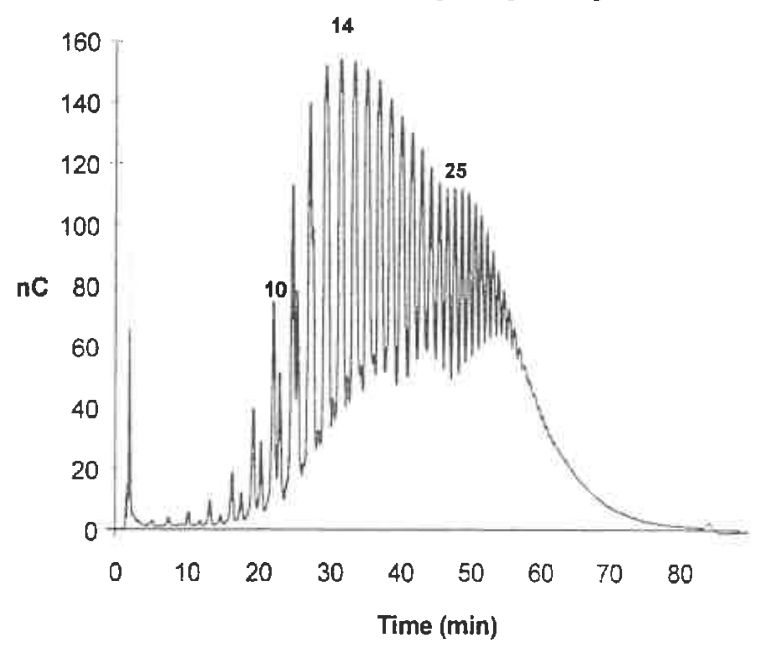

Pea $-\mathbf{2 0}$ days hydrolysis

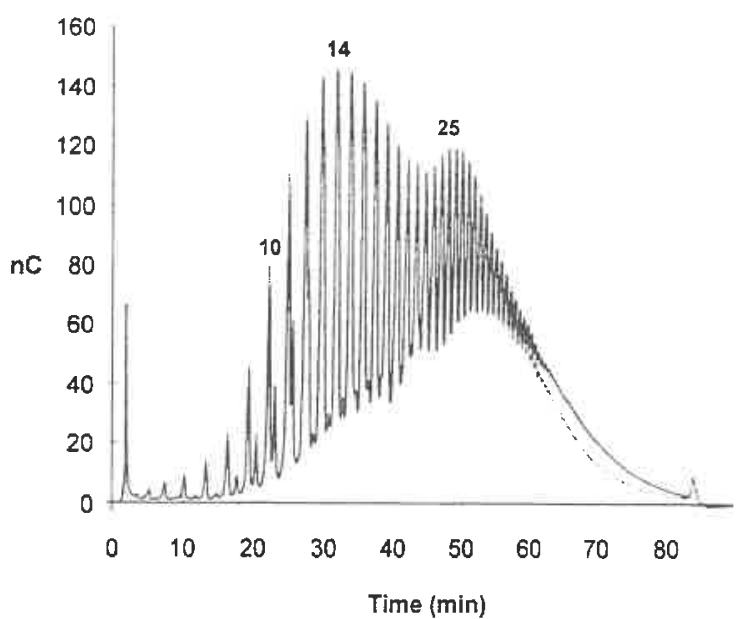

Fig. 5. HPAEC chain length distribution profiles of lintnerised native (grey line) and two step annealed (black line) wheat, potato and pea starches. 


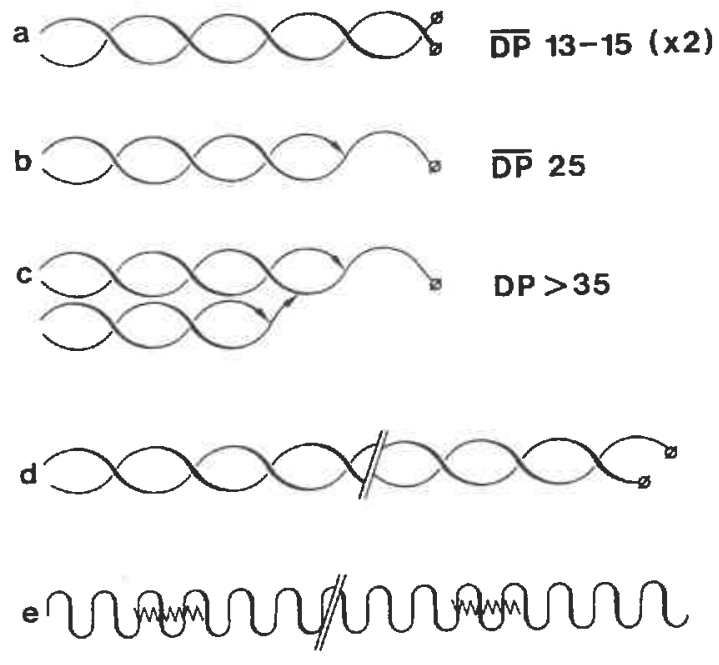

Fig. 6. Possible structures in lintnerised starches: (a) linear chains (DP 13-15) $[2,3,5]$; (b) singly branched chains (DP 25) $[2,3,5]$; (c) an example of a multiply branched chain [5]; (d) retrograded amylose [11]; (e) amylose-lipid complexes [11] (only in lipid-containing starches, as wheat starch); $\sim$, glucose residues, $\alpha-(1 \rightarrow 4)$-linked; $\varnothing$, reducing end group; $\rightarrow, \alpha-(1 \rightarrow 6)$ branch point; $\wedge \wedge \wedge \wedge$, fatty acid chain originating from a monoacyl lipid (glycerol and phosphate are removed during lintnerisation).

For 7- and 20-day lintnerised wheat starches, and 7-day lintnerised potato starches, the increase in the proportion of singly branched (DP 22-30) chains relative to the proportion of short linear (DP 10-18) chains for lintnerised annealed, compared to lintnerised native starches, may indicate that, as a result of annealing, branch points of amylopectin become more resistant to acid hydrolysis. For example, by perfection of the crystalline structure, some branch points may become more embedded in this structure and, as a result, less susceptible to hydrogen ions. For the previous samples, and also for the 20-day lintnerised pea starches, the relatively higher proportion of high DP chains $(\mathrm{DP}>35)$ for lintnerised two step annealed starches

Table 6

Ratio of peak areas in the HPAEC chromatogram of DP 22 30 chains to DP $10-18$ chains $^{\text {a }}$

\begin{tabular}{lccccc}
\hline & \multicolumn{2}{c}{7 days of hydrolysis } & & \multicolumn{2}{c}{20 days of hydrolysis } \\
\cline { 2 - 3 } \cline { 5 - 6 } & Native & $\begin{array}{r}\text { Two step } \\
\text { annealed }\end{array}$ & & Native & $\begin{array}{r}\text { Two step } \\
\text { annaeled }\end{array}$ \\
\hline Wheat & 1.14 & 1.20 & & 0.86 & 0.92 \\
Potato & 1.13 & 1.22 & & - & - \\
Pea & 0.99 & 1.07 & & 0.72 & 0.69 \\
& 0.98 & 1.06 & & 0.70 & 0.68 \\
& 1.22 & 1.22 & & 0.87 & 0.89 \\
& 1.21 & 1.21 & & 0.85 & 0.90
\end{tabular}

a Two separate HPAEC measurements for each sample (except for 20 days hydrolysed wheat starches). than for the respective lintnerised native starches, may indicate the presence of more multiply branched chains in the lintnerised annealed starches. This would again indicate an increased resistance of amylopectin branch points to acid hydrolysis, as a result of annealing, as suggested above. Taking into account the results of Morrison et al. [11] for barley starches (see above), we also suggest an increased amount of (a) amylose double helices and/or (b) amylose-lipid complexes (for wheat starches) in the annealed starches after lintnerisation. (a) Such an increased amount of amylose double helices may result from formation of amylose double helices during annealing. Alternatively, during lintnerisation, in the annealed sample more amylose chains may become mobile than in the native sample, and aggregate to form double helices, leading to a higher fraction of chains with $\mathrm{DP}>35$ in the lintner residue. (b) A higher amount of amylose-lipid complexes in the lintnerised annealed wheat starches than in lintnerised native wheat starch would result from an increased resistance of these complexes to acid hydrolysis as a result of annealing (enrichment after lintnerisation).

\section{Conclusions}

The susceptibility of potato starch to acid hydrolysis slightly decreased as a result of annealing. For wheat and pea starches no differences in susceptibility were observed between native, one step and two step annealed starches.

After lintnerisation, differences in DSC transition temperatures and peak widths between native, one step and two step annealed starches almost disappeared. Lintnerised starches could all still be annealed (increase in $T_{\mathrm{o}}$ and peak sharpening) but 7-day lintnerised wheat and pea starches were less susceptible to annealing than the respective 24-h lintners. The results suggest that the amorphous regions of the granule influence the structural changes that occur during annealing. For 7- and 20-day lintnerised wheat starches and 7-day lintnerised potato starches, the chain length distribution profiles showed a higher average DP and a slightly higher proportion of singly branched (DP 22-30) to short linear (DP 10-18) chains for the annealed than for the respective native samples. It was suggested that, as a result of annealing, the branch points of amylopectin become more resistant to acid attack, leading to a higher proportion of singly 
branched to short linear chains and a higher relative amount of multiply branched (DP $>35$ ) chains. Thus, structural changes within the crystalline zones can also take place during the annealing treatment.

The characterisation (DSC, HPAEC) of lintners of native and annealed starches thus indicates a - role of both crystalline and amorphous regions in - the molecular mechanism of annealing.

\section{Acknowledgements}

We thank the Fonds voor Wetenschappelijk Onderzoek-Vlaanderen for research positions as aspirant (H.J.) and postdoctoral research fellow (R.C.E.). Our appreciation goes to Dr A. Buléon (INRA) for helpful discussions. Technical assistance by R. Desirest at INRA, and by L. Van den Ende (KU Leuven) is gratefully acknowledged.

\section{References}

[1] K. Kainuma and D. French, Biopolymers, 10 (1971) 1673-1680.

[2] J.P. Robin, C. Mercier, R. Charbonnière, and A. Guilbot, Cereal Chem., 51 (1974) 389-406.

[3] J.P. Robin, C. Mercier, F. Duprat, R. Charbonnière, and A. Guilbot, Starch, 27 (1975) 36-45.

[4] C.G. Biliaderis, D.R. Grant, and J.R. Vose, Cereal Chem., 58 (1981) 502-507.

[5] T. Watanabe and D. French, Carbohydr. Res., 84 (1980) 115-123.

[6] S. Hizukuri, Carbohydr. Res., 147 (1986) 342-347.

[7] S. Hizukuri and Y. Maehara, Carbohydr. Res., 206 (1990) 145-159.

[8] I. Hanashiro, J. Abe, and S. Hizukuri, Carbohydr. Res., 283 (1996) 151-159.

[9] W.J. Whelan, J. Jpn. Soc. Starch Sci., 23 (1976) 101-115.

[10] R.S. Hall and D.J. Manners, Carbohydr. Res., 83 (1980) 93-101.

[11] W.R. Morrison, R.F. Tester, M.J. Gidley, and J. Karkalas, Carbohydr. Res., 245 (1993) 289-302.

[12] C.A. Knutson, Cereal Chem., 67 (1990) 376-384.

[13] R. Stute, Starch, 44 (1992) 205-214.

[14] H. Jacobs, R.C. Eerlingen, W. Clauwaert, and J.A. Delcour, Cereal Chem., 72 (1995) 480-487.

[15] H. Jacobs, R.C. Eerlingen, and J.A. Delcour, Starch, 48 (1996) 266-270.

[16] K. Lorenz and K. Kulp, Starch, 32 (1980) 181-186.

[17] M. Lauro, T. Suortti, K. Autio, P. Linko, and K. Poutanen, J. Cereal Sci., 17 (1993) 125-136.

[18] R. Hoover and T. Vasanthan, J. Food Biochem., 17 (1994) 305-325.
[19] H. Jacobs, R.C. Eerlingen, H. Spaepen, P.J. Grobet, and J.A. Delcour, Carbohydr. Res., in press.

[20] B.M. Gough and J.N. Pybus, Starch, 23 (1971) 210 212.

[21] H. Jacobs, N. Mischenko, M.H.J. Koch, R.C. Eerlingen, J.A. Delcour, and H. Reynaers, Carbohydr. Res., 306 (1998) 1-10.

[22] D.A. Yost and R.C. Hoseney, Starch, 38 (1986) 289-392.

[23] B.R. Krueger, C.A. Knutson, G.E. Inglett, and C.E. Walker, J. Food Sci., 52 (1987) 715-718.

[24] B.R. Krueger, C.E. Walker, C.A. Knutson, and G.E. Inglett, Cereal Chem., 64 (1987) 187-190.

[25] R.F. Tester and W.R. Morrison, Cereal Chem., 67 (1990) 558-563.

[26] I. Larsson and A.-C. Eliasson, Starch, 43 (1991) 227-231.

[27] J.L. Marchant and J.M.V. Blanshard, Starch, 30 (1978) 257-264.

[28] K. Kulp and K. Lorenz, Cereal Chem., 58 (1981) 46-48.

[29] M. Dubois, K.A. Gilles, J.K. Hamilton, P.A. Rebers, and F. Smith, Anal. Chem., 28 (1956) 350 356.

[30] K. Fischer, Angew. Chem., 48 (1935) 394.

[31] E. Scholz, Karl-Fischer-Titration, Springer-Verlag, Berlin, Heidelberg, New York, Tokyo, 1984.

[32] M.T. Tollier and J.P. Robin, Ann. Technol. Agric., 28 (1979) $1-15$.

[33] V. Planchot, P. Colonna, and L. Saulnier, Dosage des Glucides et des Amylases, in B. Godon and W. Loisel (Eds.), Guide Pratique d'Analyses dans les Industries Céréalières, Publications Lavoisier, 1997, pp $346-398$.

[34] A.H. Muhr, J.M.V. Blanshard, and D.R. Bates, Carbohydr. Polym., 4 (1984) 399-425.

[35] M. Kugimiya, J.W. Donovan, and R.Y. Wong, Starch, 32 (1980) 265-270.

[36] C.G. Biliaderis, T.J. Maurice, and J.R. Vose, J. Food Sci., 45 (1980) 1669-1680.

[37] J.W. Donovan and C.J. Mapes, Starch, 32 (1980) 190-193.

[38] T. Komiya and S. Nara, Starch, 38 (1986) 9-13.

[39] J.W. Donovan, Biopolymers, 18 (1979) 263-275.

[40] H.F. Zobel, Starch, 40 (1988) $44-50$.

[41] D. Cooke and M.J. Gidley, Carbohydr. Res., 227 (1992) 103-112.

[42] B. Wunderlich, Macromolecular Physics, Vol. 2. Crystal Nucleation, Growth, Annealing, Academic Press, New York, 1976.

[43] R.N. Ammeraal, G.A. Delgado, F.L. Tenbarge, and R.B. Friedman, Carbohydr. Res., 215 (1991) 179-192.

[44] Y.-C. Shi and P.A. Seib, Carbohydr. Res., 227 (1992) 131-145.

[45] Y.C. Lee, Anal. Biochem., 189 (1990) 151-162. 